\title{
EDITORIAL
}

\section{Physical activity in patients with cystic fibrosis: a new variable in the health-status equation unravelled?}

\author{
M. Decramer and R. Gosselink
}

D uring the past few years, it has become clear that in chronic respiratory disease, health status is severely impaired and that this should be a prime target for treatment, both in patients with chronic obstructive pulmonary disease (COPD) and cystic fibrosis (CF) [1, 2]. Lung function impairment is relatively poorly related to impaired health status in COPD patients [3]. The same concepts appear to apply in CF patients [2]. Indeed, evidence is available demonstrating that aerobic capacity in these patients is related to survival [4], quality of life [2] and professional achievements [5].

Exercise training programmes have been developed for chronic respiratory illness, and their popularity has increased tremendously since the late 1990s. In COPD, exercise training clearly enhances functional exercise capacity and health status and reduces the utilisation of healthcare resources [6, 7]. Indirect indications suggest it may also improve survival in these patients, but, to date, no direct evidence to this effect has been provided [6]. A clear demonstration of this effect would require a large study, which may no longer be ethically acceptable as the benefits of exercise training (in terms of functional exercise capacity and health status) have now been demonstrated beyond doubt. Similar effects were demonstrated in patients with $\mathrm{CF}$, although on average the studies were understandably smaller [8]. The prime purpose of a rehabilitation programme is to make patients more apt at performing activities of daily living, and to enhance their activity levels as a whole. The latter would allow for a change in lifestyle responsible for the maintenance of the effects of rehabilitation. Whether this is really achieved with the present rehabilitation programmes is not known.

In this context, at present, surprisingly little is known about patients' activities at home. So far, subjective methods, such as activity questionnaires and diaries, are being used to assess patients' activities $[9,10]$. Although these methods have shown limited validity and reliability [11], they provide a patient's personal perception of functional status, effort and difficulties in performing activities [12]. Recently, this activity has become directly measurable by means of pedometers and accelerometers [13]. Uni-axial accelerometer measures vertical

Respiratory Rehabilitation and Respiratory Division, University Hospital, Faculty of Medicine and Faculty of Kinesiology and Rehabilitation Sciences, Katholieke Universiteit, Leuven, Belgium.

CORRESPONDENCE: M. Decramer, Chief Respiratory Division, University Hospital, Respiratory Division, Herestraat 49,3000 Leuven, Belgium. Fax: 32 16346803.E-mail: Marc.Decramer@ uz.kuleuven.ac.be acceleration and provides activity counts. In COPD patients, tri-axial accelerometers were used to measure body positions, movement patterns and the intensity at which movements are performed. This allows measurement of the time spent by the patient in active conditions, such as standing and walking, versus passive conditions like sitting and lying down. These measurements were shown to be reliable as they were in close accordance to the data obtained by video recording [13]. By way of contrast, patient estimations of their activity proved to be less reliable as they did not correlate well with the objective measurements. Patients consistently overestimated the time walking and underestimated the time standing [13].

The results of measurement of activity levels in COPD patients by PITTA et al. [14] were really remarkable. In stable patients, it was demonstrated that the time spent in an active position in COPD patients, such as walking, was very limited. It was only $6 \%$ in patients with COPD compared with $11 \%$ in the healthy elderly. Time spent standing was only $27 \%$ in COPD patients versus $41 \%$ in the healthy elderly. Walking time was poorly related to pulmonary function, but best related to the 6-min walking distance (6MWD; $\mathrm{r}=0.76, \mathrm{p}<0.0001)$. Also the relationship to peak oxygen uptake $\left(V^{\prime} \mathrm{O}_{2}\right.$,peak $)$ was relatively poor $(\mathrm{r}=0.33, \mathrm{p}<0.05)$. The good relationship with 6MWD confirmed the older concept that $6 \mathrm{MWD}$ was related to activities in daily living and better so than $V^{\prime} \mathrm{O}_{2}$,peak.

This means that the tools to study patients in their normal activities are now available. Thus, the first studies seem to confirm important inactivity in COPD patients. In addition, this inactivity is severely enhanced in COPD exacerbations, stressing the importance of this factor in the generation of the muscle weakness that occurs in these patients [15]. Finally, we can study under what conditions rehabilitation improves activity levels.

An array of devices is presently available to measure patient activity. In the present issue of the European Respiratory Journal, HEBESTREIT et al. [16] used a MTI/CSA 7164 accelerometer (MTI Health Services, Fort Walton Beach, FL, USA), a uni-axial accelerometer, to assess periods of moderate and vigorous physical activity (MVPA), and an average daily accelerometer count (ADAC) in patients with CF. This device does not allow the measurement of movement patterns, but gives a rough idea of movement intensity. HeBESTREIT et al. [16] studied a total of 71 patients, making this study large in the context of CF. Interestingly, they found that both MVPA and ADAC independently explained part of the variance in maximal oxygen uptake $\left(V^{\prime} \mathrm{O}_{2}, \max ; 3.7\right.$ and $2.5 \%$ of the variance, 
respectively), after correcting for the effects of body size, sex, lung function and muscle power. Clearly, this relationship was not caused by the expected relationship between muscle power and $V^{\prime} \mathrm{O}_{2}$,max. This is the first study to extend the observations that were recently made on COPD patients, and cited previously, to patients with CF.

Whether activity levels determine $V^{\prime} \mathrm{O}_{2}$,peak or whether $V^{\prime} \mathrm{O}_{2}$,peak determines activity levels cannot be determined from the study by HEBESTREIT et al. [16], as only correlations were studied. The answer to the former question would require some sort of intervention study examining the effects of exercise training on activity levels, and studies in which activity levels are varied by patient instruction without exercise training. Such studies still need to be performed. Although there is some evidence that suggests rehabilitation enhances $V^{\prime} \mathrm{O}_{2}$,peak in cystic CF $[17,18]$, at present there are no studies examining the effects of rehabilitation on activity levels, nor is there any evidence that rehabilitation would be the only way to enhance activity levels in these patients.

Nevertheless, the present study extends observations that were made in chronic obstructive pulmonary disease patients, and stresses that peak oxygen uptake and activity levels [19] may be related to health status in patients with cystic fibrosis as well. In this way, it also contributes to further understanding of the factors determining health status in these patients. This is without question a necessary step towards optimal improvement of health status in cystic fibrosis patients.

\section{ACKNOWLEDGEMENTS}

The authors would like to thank the Fonds voor Wetenschappelijk Onderzoek-FWO Vlaanderen (Brussels, Belgium) and the Foundation Van Goethem-Brichant (Brussels, Belgium) for the support of the studies mentioned. The authors would also like to thank F. Pitta and T. Troosters for the stimulating discussion we had on this subject.

\section{REFERENCES}

1 Spencer S, Calverley PM, Sherwood Burge P, Jones PW, Isolde Study Group. Health status deterioration in patients with chronic obstructive pulmonary disease. Am J Respir Crit Care Med 2001; 163: 122-128.

2 Orenstein DM, Nixon PA, Ross EA, Kaplan RM. The quality of well-being in cystic fibrosis. Chest 1989; 95: 344-347.

3 Jones P, Quirk FH, Baveystock CM, Littlejohns P. A selfcomplete measure of health status for chronic airflow limitation. The St. George's Respiratory Questionnaire. Am Rev Respir Dis 1992; 145: 1321-1327.

4 Nixon PA, Orenstein DM, Kelsey SF, Doershuk CF. The prognostic value of exercise testing in patients with cystic fibrosis. N Engl J Med 1992; 327: 1785-1788.

5 Selvadurai HC, Blimkie CJ, Meyers N, Mellis CM, Cooper PJ, Van Asperen PP. Randomized controlled study of in-hospital exercise training programs in children with cystic fibrosis. Pediatr Pulmonol 2002; 33: 194-200.

6 Troosters T, Casaburi R, Gosselink R, Decramer M. Pulmonary rehabilitation in chronic obstructive pulmonary disease. Am J Respir Crit Care Med 2005; 172: 19-38.

7 Lacasse Y, Brosseau L, Milne S, et al. Pulmonary rehabilitation for chronic obstructive pulmonary disease. Cochrane Database Sys Rev 2002; 3: CD003793.

8 Bradley J, Moran F. Physical training for cystic fibrosis. Cochrane Database Sys Rev 2002; 2: CD002768.

9 Lareau SC, Meek PM, Roos PM. Development and testing of the modified version of the pulmonary functional status and dyspnea questionnaire (PFSDQ-M). Heart Lung 1998; 27: 159-168.

10 Bestall JC, Paul EA, Garrod R, Garnhan R, Jones PW, Wedzicha JA. Usefulness of the Medical Research Council (MRC) dyspnoea scale as a measure of disability in patients with chronic obstructive pulmonary disease. Thorax 1999; 54: 581-586.

11 Shephard RJ. Limits to the measurement of habitual physical activity by questionnaires. Br J Sports Med 2003; 37: 197-206.

12 Pitta F, Troosters T, Spruit MA, Decramer M, Gosselink R. Activity monitoring for assessment of physical activities in daily life in patients with chronic obstructive pulmonary disease. Arch Phys Med Rehabil 2005; 86: 1979-1985.

13 Pitta F, Troosters T, Probst VA, Spruit MA, Decramer M, Gosselink R. Quantifying physical activity in daily life with questionnaires and motion sensors in COPD. Eur Respir J 2006; 27: 1040-1055.

14 Pitta F, Troosters T, Spruit MA, Probst VA, Decramer M, Gosselink R. Characteristics of physical activities in daily life in chronic obstructive pulmonary disease. Am J Respir Crit Care Med 2005; 171: 972-977.

15 Pitta F, Troosters T, Probst VA, Spruit MA, Decramer M, Gosselink R. Physical activity and hospitalization for exacerbation of COPD. Chest 2006; 129: 536-544.

16 Hebestreit H, Kieser S, Rüdiger S, et al. Physical activity is independently related to aerobic capacity in cystic fibrosis. Eur Respir J 2006; 28: 734-739.

17 Orenstein DM, Franklin BA, Doershuk CF, et al. Exercise conditioning and cardiopulmonary fitness in cystic fibrosis. The effects of a three-month supervised running program. Chest 1981; 80: 392-398.

18 Klijn PH, Oudshoorn A, van der Ent CK, van der Net J, Kimpen JL, Helders PJ. Effects of anaerobic training in children with cystic fibrosis: a randomized controlled study. Chest 2004; 125: 1299-1305.

19 Klijn PH, Nieuwenhuis M, van Stel H, et al. Validation of the Dutch pediatric cystic fibrosis quality of life questionnaire. In: Klijn PHC, ed. Physical Fitness and Quality of Life in Children with Cystic Fibrosis. Utrecht, Labor Grafimedia, 2003; pp. 41-57. 